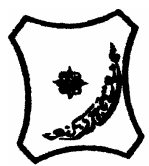

Bayero Journal of Pure and Applied Sciences, 8(2): 58 - 67

Received: August, 2015

Accepted: November, 2015

ISSN 2006 - 6996

\title{
GROWTH TECHNIQUES USED TO DEVELOP Cds/CdTe THIN FILM SOLAR CELLS: A REVIEW
}

\author{
Diso, D. G., ${ }^{1 *}$ Bichi, T. S., ${ }^{1}$ Hotoro, M. A. Y., ${ }^{1}$ Faragai, I. A. ${ }^{1}$ and Musa, A. $0 .{ }^{2}$ \\ ${ }^{1}$ Department of Physics, Kano University of Science \& Technology, Wudil, PMB 3244, Kano-Nigeria. \\ ${ }^{2}$ Department of Physics, Bayero University, Kano, PMB 3011, Kano-Nigeria. \\ *Corresponding author: dgdiso@yahoo.co.uk, Mobile number: +234 (0) 8028053014
}

\begin{abstract}
The method used to grow thin film CdS/CdTe solar cells has been described. Electronic material layers usually grow in three different modes; layer-by-layer growth mode, layer and cluster growth mode (Stransky-Krastanov) and cluster formation growth mode. Techniques such as molecular beam epitaxy (MBE), metal organic chemical vapour deposition (MOCVD) called melt growth or Bridgman are well known as high quality semiconductor growth techniques. One of the limitations of these techniques is the inability for manufacturing macro-electronic devices ( area $1 \mathrm{~m}^{2}$ ) such as photovoltaic (PV) panels and large area display devices. To grow large area thin film (semiconductors), growth techniques such as close space sublimation (CSS), electrodeposition (ED), sputtering, spray pyrolysis etcetera have been tested and employed. This paper reviews in depth most of these techniques with more emphasis on the electrodeposition method because of it is simplicity and low cost.

Keywords: Growth Techniques, CdS, CdTe, Thin Films, Solar Cells.
\end{abstract}

\subsection{INTRODUCTION}

The techniques used to grow CdS/CdTe thin films include Vapour-phase deposition comprising of physical vapour deposition (PVD) and chemical vapour deposition (CVD) and Liquid-phase or solution deposition such as chemical solution deposition (CSD) and electrochemical deposition (ECD) (Chopra and Das, 1983).

2.0 Physical Vapour Deposition (PVD)

The PVD includes sputtering and thermal evaporation.

The deposition of the material on the substrate is by physical means. A material to be deposited is heated above its melting point in an evacuated chamber, and evaporation occurs.

2.1 Sputtering: This is a process whereby atoms/molecules are ejected from a solid target material due to bombardment of the target by energetic particles. Sputtering is also defined as erosion of solid surfaces during ion bombardment (Smentkowski, 2000). Figure 1 shows the schematic set-up for sputtering process.

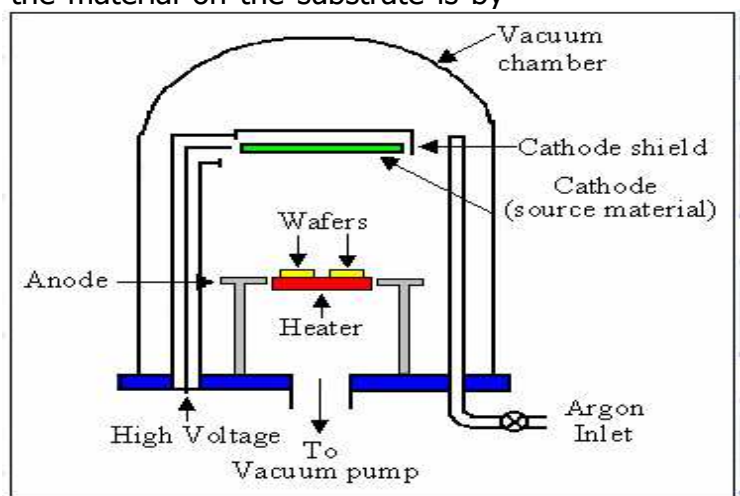

Figure 1: $\quad$ Schematic set-up for sputtering technique (wwwold.ece.utep.edu, 2015).

An inert gas (usually argon) is introduced at low pressure into the vacuum chamber where the substrate and the source material are placed. The gas becomes ionized after gas plasma is bombarded using an RF power source. The accelerated ions move towards the surface of the target and cause the breakup of the atoms from the source in vapour form which then condense on a substrate to form a film. (Mandal et al., 1999) have grown CdTe thin films by this technique. The deposition of CdS thin films was also successful as reported in the literature (Taneja et al., 2002). 
2.2 Thermal evaporation: In this technique, a solid material is placed in a boat which is heated to the point where it starts to evaporate and later condenses onto a cooler substrate to form a film. The evaporation rate depends on the crystal face from which evaporation takes place. The vacuum pressure is less than $10^{-3} \mathrm{~Pa}$ for good coating (Pierson, 1999).
Figure 2 shows a set-up for thermal evaporation technique. CdTe thin films have been deposited by (Ali et al., 2008) by this method, using Cd granules and Te powder placed inside a boat at $\sim 10^{-6} \mathrm{mbar}$ vacuum pressure. (Lee et al., 1999) grew CdS thin films using this technique.

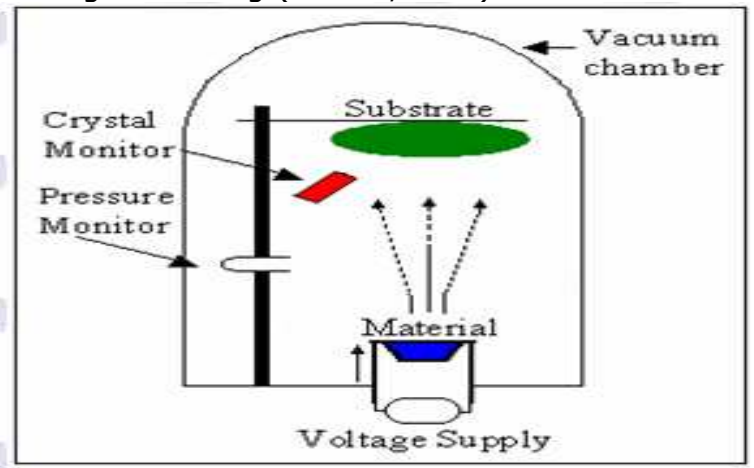

Figure 2: Thermal evaporation technique set-up (wwwold.ece.utep.edu, 2015).

\subsection{Chemical vapour deposition (CVD)}

The CVD is also known as vapour-phase epitaxy (VPE). It involves depositing a solid material from a gaseous phase. The deposition must be carried out in pressure ranging anywhere from several atmosphere down to high vacuum (Chopra and Das, 1983). At approximately ambient temperature, the precursor gases are delivered into the reaction chamber and pass over or come in contact with a heated substrate. (Choy, 2003) reported that, the formation of the stable solid is due to the dissociation and/or chemical reactions of gaseous reactants in activated (heat,

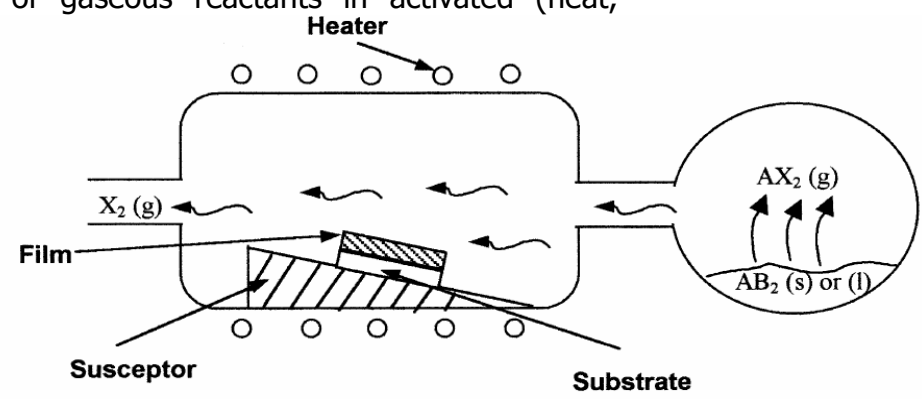

Figure 3: $\quad$ Schematic diagram of CVD process (Choy, 2003).

3.1 Metal-organic CVD (MOCVD): An epitaxial layer is deposited using this technique. Organic molecules (precursors) are decomposed thereby release atoms while passing over the hot substrate in which the deposition occurs. The precursors are metal-organic and generally undergo decomposition or pyrolysis reactions. It was reported in the literature (Choy, 2003) that MOCVD reaction process is kinetically limited at deposition temperatures below $500^{\circ} \mathrm{C}$. When the temperature is in the ranges (550 $750)^{\circ} \mathrm{C}$, diffusion-rate reaction is limited and at temperature of $800^{\circ} \mathrm{C}$, the reaction is limited by homogenous reaction. The growth of $\mathrm{CdS}$ and $\mathrm{CdTe}$ thin films has been reported (Berrigan et al., 1998) using this technique. CdS is nucleated from dimethylcadmium and ditertiarybuttylsulphide at $290^{\circ} \mathrm{C}$. CdTe deposition is from DMCd and diisoprophyltelluride at $300-310^{\circ} \mathrm{C}$. light, plasma) environment. CVD equipment consists of three main components as follows:

- chemical vapour precursor supply system

- CVD reactor and

- effluent gas handling system.

Figure 3 shows a schematic diagram of a CVD process. A comprehensive review of this technique has been reported in the literature (Lee et al., 1999). CVD technique includes Plasma CVD and Metalorganic CVD (MOCVD) among others.
3.2 Molecular Beam Epitaxy (MBE): This is a high vacuum epitaxial growth technique via the interaction of several molecular or atomic beams on the heated substrate surface. Epitaxial films of a wide variety of materials, ranging from oxides, semiconductors and metals can be deposited. Figure 4 shows a schematic front view of a basic MBE growth chamber. The source ovens are used to evaporate the constituent molecules or atoms and direct them to the substrate which is mounted on a heater block. The beams are switched on and off through mechanical shutters driven from outside the vacuum chamber. The system background pressure remains very low due to the chilled walls surrounding the source ovens and the substrate; this makes the beams to have a single pass through the chamber before condensing on the walls. 
The reflection high energy electron diffraction (RHEED) gun operates without damage from corrosive reaction without residual vapour. This produces a high purity growing film.

The deposition takes place at pressure $\sim 10^{-8} \mathrm{~Pa}$ in a high vacuum system. The deposition rate is very slow (typically < $1000 \mathrm{~nm}$ per hour); this gives epitaxial layers on the deposited substrate. Quasi-Knudsen effusion cells are used to heat the elements and as a result the elements sublime, to condense later on the target substrate. Two of the limitations on MBE growth are slow process and the very expensive equipment used. Large area deposition is not possible. (Boieriu et al., 2000) have grown CdS by this technique using a $\mathrm{Cd}$ flux and a valves $\mathrm{S}$ cracker cell with a source temperature of $130^{\circ} \mathrm{C}-135^{\circ} \mathrm{C}$ and a cracking zone of $500^{\circ} \mathrm{C}$. A conventional effusion cell was used as in source for n-type doping. Growth temperatures between $150^{\circ} \mathrm{C}$ and $350^{\circ} \mathrm{C}$ were used and the pressure range was $6 \times 10^{-8}$ to $1.5 \times 10^{-7}$ Torr. The deposition growth rate was $\sim 0.3 \mathrm{nms}^{-1}$. Similarly, the deposition of CdTe using this technique has been reported using CdTe crystal as the source at a growth rate of $0.3 \quad \mu \mathrm{mh}^{-1}$.

Figure 4: $\quad$ Schematic front view of a basic MBE growth chamber (Arthur, 2002).

3.4 Close Space Sublimation (CSS):The CSS growth technique is described as follows (Alamri, 2003); (a) Diffusion-limited transport: The deposited materials migrate to the substrate through the ambient gas and collide several times with gas molecules before condensing on the substrate. (b) Langmuir's theory: The deposited materials are moved directly to the substrate without any gas phase collision.

The schematic diagram of the CSS system is shown in Figure 5 (a) and (b) shows the position of the source and substrate sandwiched in the growth chamber. The source and substrate are separated by spacers enclosed in a reaction chamber and held between two graphite susceptors inside a quartz reactor. The source of heating is from visible or infra-red lamps outside the reactor facing the blocks of graphite. A set of thermocouples monitored the temperature of the graphite blocks for both the source and the substrate temperatures. A diffusion controlled transport

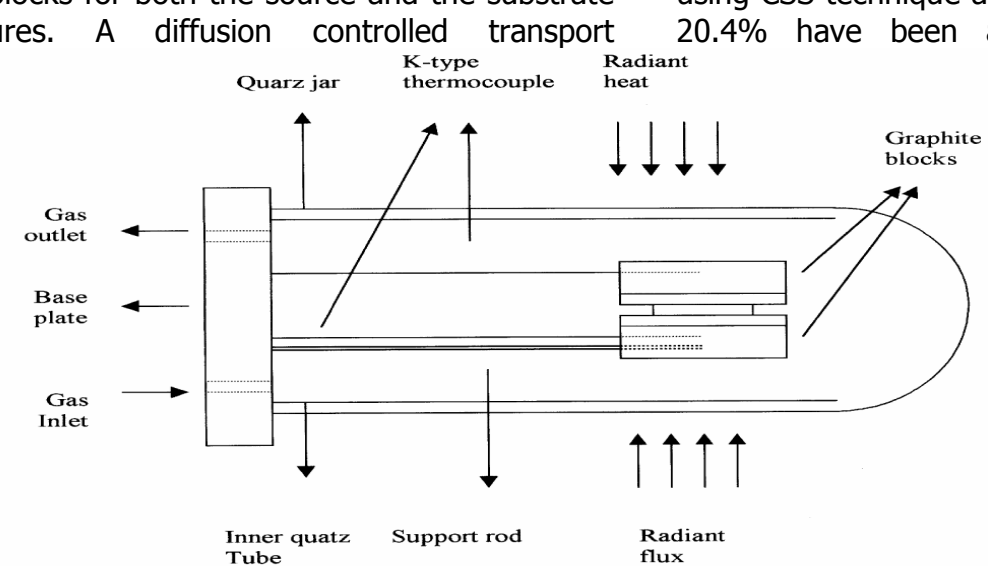

Figure 5 (a): Schematic of the CSS system (Seth et al., 1999). mechanism takes place during the temperature difference and the material from the source transfers to the substrate. The deposition rate depends upon the source, spacing, substrate temperature and ambient gas nature. The material to be deposited is placed on a boat and heated by a halogen lamp $\sim 1000 \mathrm{~W}$. This lamp is connected to the main power through temperature controller with K-type thermocouple. The substrate is heated by a second halogen lamp $\sim 500 \mathrm{~W}$ at a distance of $1-4 \mathrm{~mm}$ from the source material. Deposited material is now condensed on the heated substrate due to reduced temperatures.

(Han et al., 2010) have grown CdS thin films by this technique using CdS crystal. The source temperature was $680^{\circ} \mathrm{C}$ and substrate was kept at $520^{\circ} \mathrm{C}$. CdS thin films were deposited in 20 minutes with a thickness $\sim 150 \mathrm{~nm}$. The world record CdTe thin films solar cells using CSS technique and devices with an efficiency of $20.4 \%$ have been achieved (First solar, 2014). 


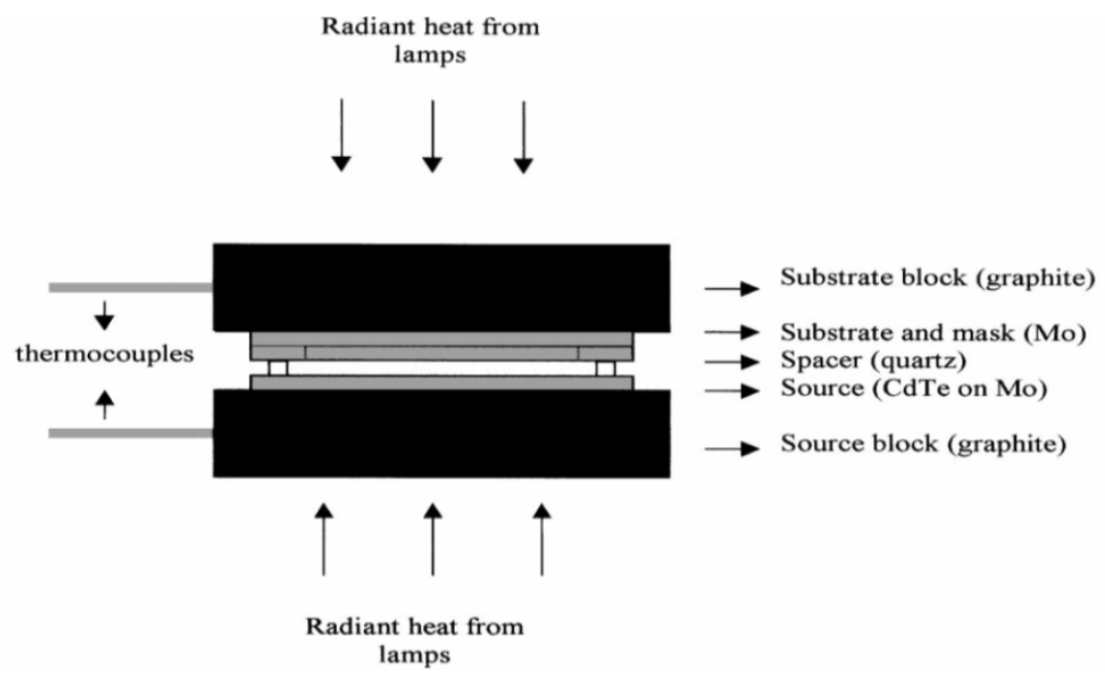

Figure 5 (b): Schematic showing the source and the substrate sandwiched in the growth chamber (Seth, 1999).

\subsection{Liquid-phase deposition}

This technique involves liquid medium as the means of deposition and is always present in ionic form. It involves inherently chemical and/or electrochemical reactions for the formation of the deposit material. The deposition is normally at low temperature and no vacuum is required.

4.1 Spray pyrolysis: This is a non-vacuum technique and the deposition can be scaled up for industrial applications. In this method, a solution containing material precursor ions, in form of droplets is sprayed onto a heated substrate in air from the source to form a coating. The sprayed solution is diluted either in water or alcohol or both. The temperature of the substrate is at $350^{\circ} \mathrm{C}-500^{\circ} \mathrm{C}$. Figure 6 shows a typical spraying system (Patil, 1999). The main components of the system are; substrate heater, temperature controller, air compressor and spray nozzle. The quality of the films produced by this technique depends upon some parameters which include the spray rate, substrate temperature, droplet size, cooling rate, carrier gas and ambient atmosphere.

CdS thin film can be deposited by this technique using equal concentrations of $\mathrm{Cd}^{2+}$ and $\mathrm{S}^{2-}$ ions (Toušková et al., 1992). The glass/FTO substrate is heated to $420^{\circ} \mathrm{C}$ and $\mathrm{CdS}$ films deposited directly on the substrate. CdTe thin films of thickness $1-4 \mu \mathrm{m}$ have been deposited by this technique. The molarity of CdTe was $0.0375 \mathrm{M}$ and the deposition time was $15-$ 60 minutes. The spray rates were $3-5 \mathrm{ml}$ per min and the substrates temperature during this deposition ranged from $425-500^{\circ} \mathrm{C}$ (Berry, 1996).

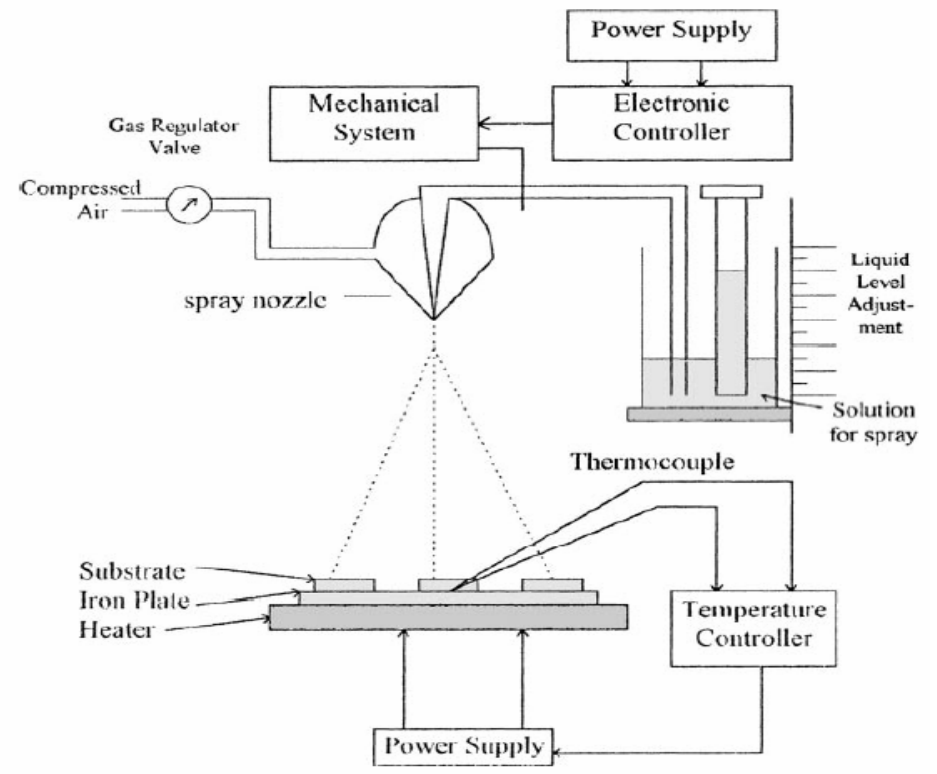

Figure 6: $\quad$ Schematic set-up for spray pyrolysis technique (Patil, 1999).

4.2 Screen printing: This is a technique that uses a woven mesh to support an ink-blocking stencil and transfers the ink or other materials pressed through the mesh as a sharp image onto a substrate. The active material is carried to the surface of the substrate using a paste as shown in Figure 7. The paste can be organic solvent, conducting material or glass frit (Luque and Hegedus, 2003). Pressure is applied to the squeegees after the paste has been dispensed; this makes the screen to be in contact with the substrate. 
Bajopas Volume 8 Number 2 December, 2015

The squeegees are moved to and fro of the screen and releasing the paste in front of it by dragging and pressing it. The substrate and the screen should not be in contact, the distance separating them is called the snap-off.

(Arita et al., 1991) have grown CdS thin film by this technique using CdS paste deposited on a glass substrate. The growth of CdTe thin film have also been reported (Kumar et al., 2006) using a slurry consisting of CdTe powder, $10 \%$ wt. of $\mathrm{CdCl}_{2}$ and an appropriate amount of ethylene glycol. $\mathrm{CdCl}_{2}$ was used as an adhesive and ethylene glycol as a binder. Paste prepared was screen printed on ultra clean glass substrate.

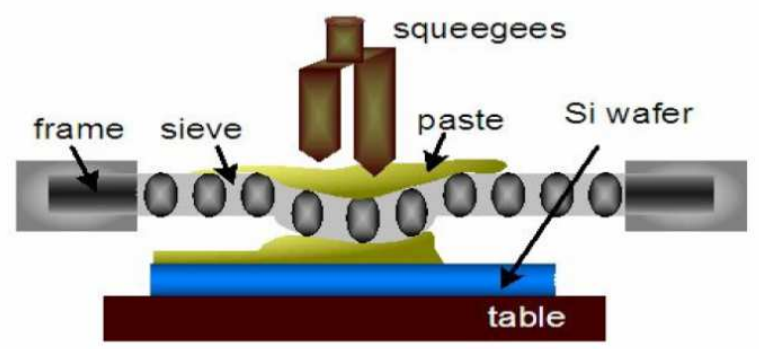

Figure 7: $\quad$ Schematic set-up of screen printing technique (Kumar et al., 2006). $4.3 \quad$ Inkjet printing: This is the technique in which
tiny droplets (with a diameters in the range $50-100$ $\mu \mathrm{m})$ (Tekin et al., 2003) composed of either solution or dispersion of functional materials are ejected onto addressable sites on a substrate. A fixed quantity of ink in chamber is ejected from a nozzle through a sudden, quasi-adiabatic reduction of the chamber volume via piezoelectric action as shown in Figure 8. The liquid is contracted in response to the application of an external voltage from a chamber. A shockwave is set up in the liquid upon the sudden reduction in its volume. As a result, a liquid drop is ejected from the nozzle. Under the action of gravity and air resistance, the ejected drop impinges on the substrate, spreads on the surface and dries through solvent evaporation. It was reported in the literature (Tekin et al., 2003) that CdTe Nanocrystal polymer was grown by this technique using solution of CdTe NCs containing 1 wt $\%$ PVA, in which the amount of ethylene glycol varied from $0-20$ vol $\%$.

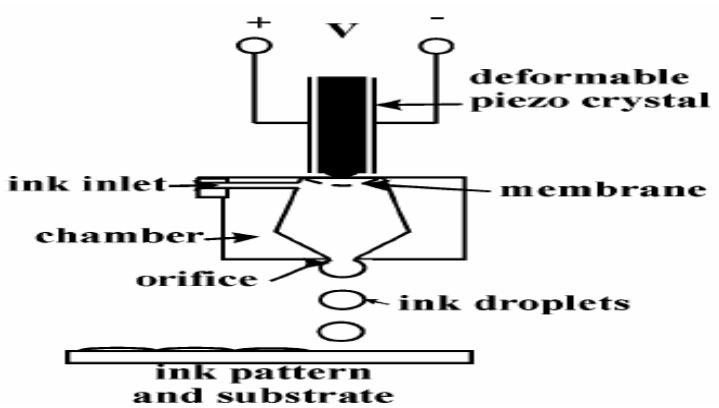

Figure 8: $\quad$ Inkjet printing set-up (Parashkov et al., 2008).

4.4 Chemical Bath Deposition (CBD): This technique using a liquid chemical solution containing technique involves manipulated precipitation in which a chemical reducing agent in solution reduces metallic ions to the metal. One of the disadvantages of using CBD is sulphur and CdS precipitation in the electrolytic bath and generation of Cd-containing waste in the CdS deposition. Semiconductor materials such as CdS and $\mathrm{ZnS}$ are the most common materials grown using this technique. Figure 9 shows a typical set-up of CBD technique. (Han et al., 2010) have grown CdS by this $1.5 \times 10^{-3} \mathrm{molL}^{-1}$, cadmium acetate and $5 \times 10^{-2}$ $\mathrm{molL}^{-1}$ thiourea. The bath temperature is $\sim 75^{\circ} \mathrm{C}$ and $\mathrm{pH} \sim 11.0$. Thin film CdS deposited on the substrate in 60 minutes had thickness of approximately $150 \mathrm{~nm}$. CdTe thin films deposition have also been reported using this technique (Deivanayaki et al., 2010). 0.1M of Cadmium acetate solution was prepared and $0.2 \mathrm{M}$ of ammonia aqueous was added drop wise until clear solution was obtained.

Figure 9:

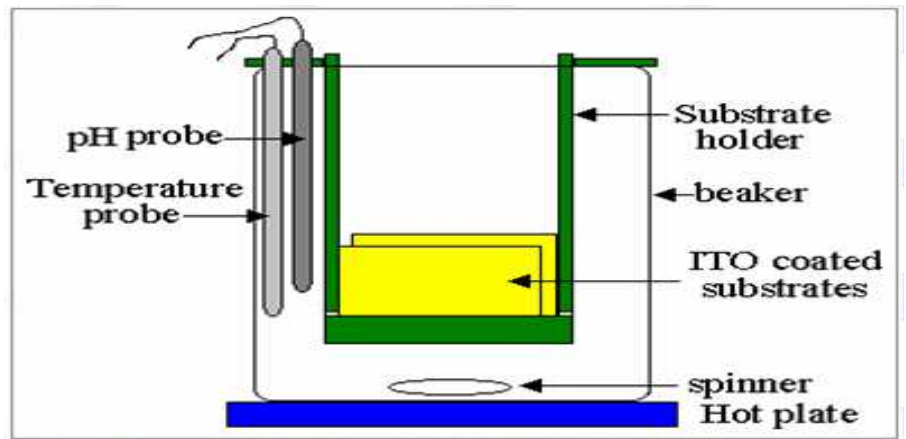

Typical CBD set-up (Utep, 2014). 


\subsection{Electrodeposition (ED)}

5.1 Overview of electrodeposition: The first semiconductor electrodeposited is elemental silicon (Ulik, 1865) using electrolysis containing a solution of $\mathrm{K}_{2} \mathrm{SiF}_{6}$ in $\mathrm{KF}$. Silicon electrodeposition began in the 1930's after an intensive systematic research (Ddero, 1934). The electrochemical synthesis of III-V compounds started with GaP (Cuombo and Gambino, 1968) and a thickness up to $100 \mu \mathrm{m}$ of GaP on silicon substrate was obtained. DeMattei et al., 1978 reported the electrodeposition of GaAs. An electrolyte in the form of molten salt solution was used which contained $\mathrm{NaAsO}_{2}$ and $\mathrm{Ga}_{2} \mathrm{O}_{3}$ in $\mathrm{a} \mathrm{B}_{2} \mathrm{O}_{3}-\mathrm{NaF}$ solvent at $720-760^{\circ} \mathrm{C}$.

Hodes et al., 1976 first reported the aqueous electrodeposition of II-VI compound semiconductor (CdSe) and it was grown on titanium substrate. The anodization of cadmium and bismuth in polysulphide solution produced the $\mathrm{CdS}$ and $\mathrm{Bi}_{2} \mathrm{~S}_{3}$ in 1976 (Miller and Heller, 1976). Panicker et al., 1978 reported the electrodeposition of CdTe from aqueous solution using $\mathrm{CdSO}_{4}$ and $\mathrm{TeO}_{2}$. The deposition was carried out

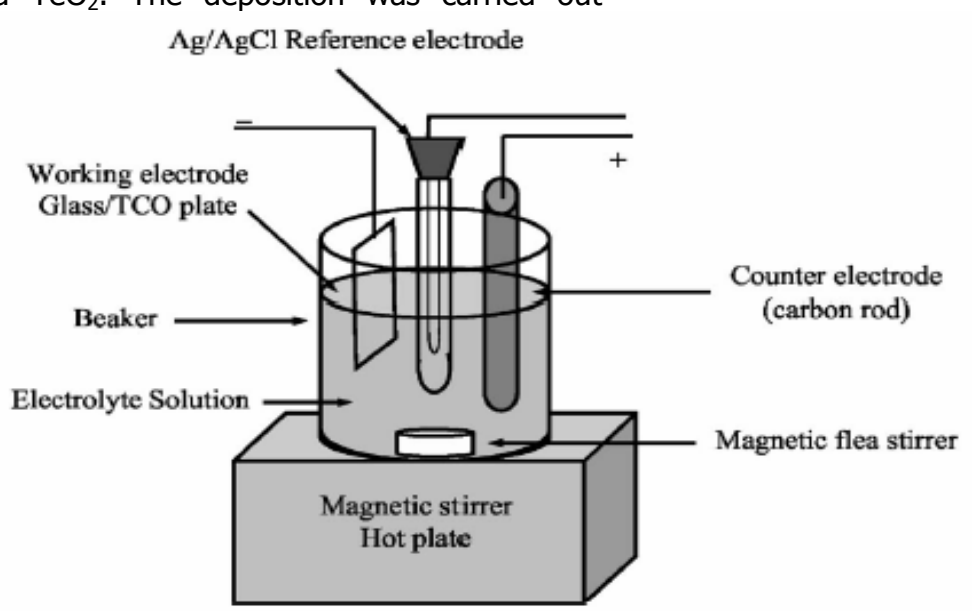

Figure 10 (a): Typical set-up of three electrode system (Dharmadasa and Haigh, 2006).

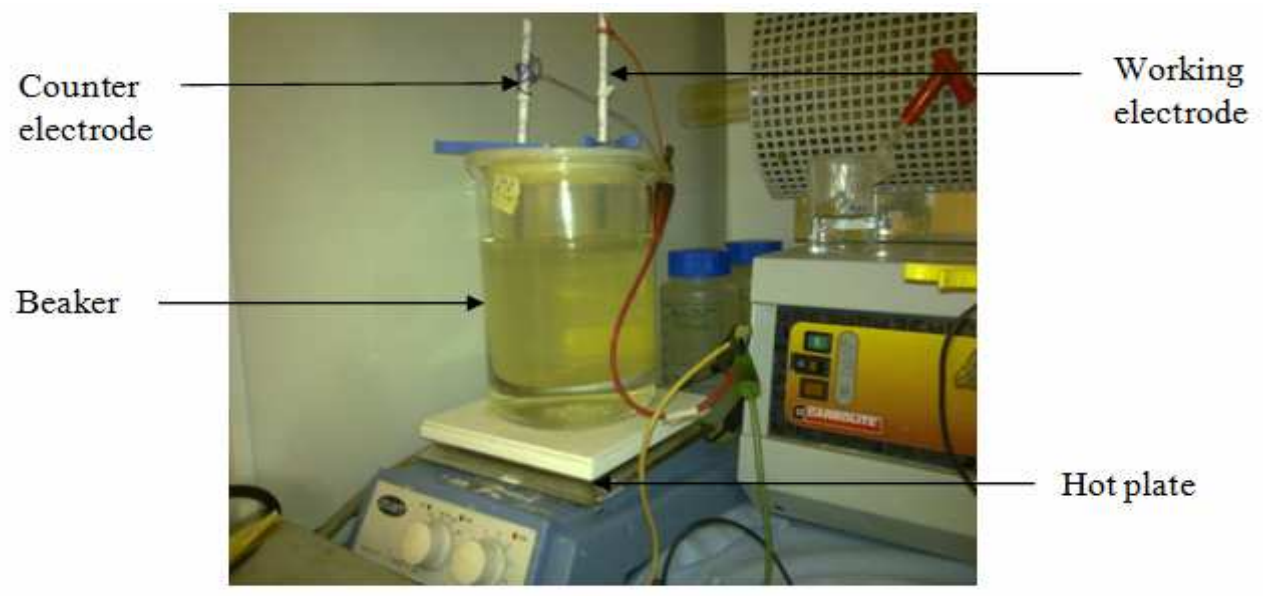

Figure 10 (b): A photograph of a typical two electrode set-up.

An ED system consists of an electrolyte, two electrodes and a power supply (for two electrodes system). The electrolyte must be electrically conductive and it can be aqueous, non-aqueous or molten and must contain suitable metal salts. The electrodes must consist of at least the cathode using three electrode cells. A conversion efficiency of $0.4 \%$ has been achieved on electrodeposited CdTe deposited on titanium substrate (Danaher, 1978). Electrodeposition of CdS started using an aqueous solution containing $\mathrm{Cd}^{2+}$ and $\mathrm{SO}_{3}^{2-}$ ions in 1981 (MaCann and Skyllas, 1981).

5.2 Electrodeposition in General: The deposition of a substance on an electrode by the action of an external source (electricity) is known as electrodeposition (ED). It is carried out in an electrochemical cell consisting of a reaction vessel of two or three electrodes. In the two electrode cell, the reaction is controlled by the current applied between the working electrode and counter electrode. A reference electrode is used to control or measure the potential of the working electrode in the three electrode cells, and the deposition is carried out by controlling the current whilst monitoring the potential, or by controlling potential whilst measuring the current. Figures 10 (a) and (b) show typical set-ups of three and two electrode systems respectively. 
As reported in the literature (Dharmadasa and Haigh, 2006), the use of reference electrode in electrodeposition such as standard calomel or $\mathrm{Ag} / \mathrm{AgCl}$ may be a problem because if such ions (especially $\mathrm{Ag}^{+}$) leaks into the bath, it poisons the bath and therefore reduces the efficiencies of the solar cells. This result has been confirmed (Dennison, 1994).

$E D$ is a non-vacuum technique and it offers excellent control over the properties of the thin films through the influence of parameters such as deposition potential, bath temperature, $\mathrm{pH}$, deposition time and electrolytes concentration (Pandey et al., 1996). In comparison with $\mathrm{CBD}$, which is the other common liquid phase deposition technique, ED is more readily controlled and the precursor solutions are stable. ED has the additional advantages of very high utilization of constituent chemicals, which reduces the amount of Cd-containing waste generated. Films can be deposited onto the desired area of the substrate and the electrolyte can be used for a long period of time. One of the main disadvantages of ED is that the substrate must be conductive and its sheet resistance must be low. CdTe films have been electrodeposited by British Petroleum (BP) Company, and CdTe solar panels were manufactured. The plant had eight identical reaction chambers, each tank capable of handling $40,0.55 \mathrm{~m}^{2}(14 " \times 61 ")$ substrates or 24 , $0.94 \mathrm{~m}^{2}(24 " \times 61 ")$ substrates (Cunnigham, 2000). In 2001, BP produced CdTe modules with area of 0.81 $\mathrm{m}^{2}$ and has conversion efficiency $10.7 \%$ (Green et al., 2007).

In general terms, the reaction in the aqueous medium involved in electrodeposition is governed by Faraday's two laws. These laws were discovered in 1843 by Michael Faraday (Pandey et al., 1996).

Faraday's $1^{\text {st }}$ Law of Electrolysis states that the mass of a substance altered at an electrode during electrolysis is directly proportional to the quantity of electricity transferred at the electrode. "Quantity of electricity" refers to electrical charge, typically measured in Coulombs.

Faraday's $2^{\text {nd }}$ Law of Electrolysis states that the masses of the different substances liberated in the electrolysis are proportional to their chemical equivalent weights.

Faraday's laws can be summarized (Pandey et al., 1996) as:

$$
m=\left(\frac{Q}{F}\right)\left(\frac{M}{z}\right)
$$

Equation (1) gives the Faraday's equation which is used to calculate the theoretical thickness of the deposited films:

$$
T=\frac{1}{n F A}\left(\frac{i t M}{\rho}\right)
$$

where $m$ is the mass of the substance altered at an electrode, $Q$ is the total electric charge passed through the substance, $F=96,485 \mathrm{Cmol}^{-1}$ is the Faraday constant, $M$ is the molar mass of the substance, ' is the density of the deposited film, $i$ is the average current density, $A$ is the area, $T$ is the thickness, $t$ is the time and $z$ is the valence number of ions of the substance (electrons transferred per ion). The cell potential $E$ is related to the Gibbs free energy from the thermodynamic view. It is the chemical potential when a system reaches equilibrium at constant temperature and pressure and this change in the free energy is given (Pandey et al., 1996):

$$
\Delta G=-n F E
$$

where, $E$ is the electrochemical cell potential and $n$ is the electron number.

The sign of $\Delta G$ gives the direction of the reaction; at positive potential, the free energy is negative which makes the reaction spontaneous. The free energy is positive at negative potential and therefore the reduction reaction must be forced. The Nernst equation is used to measure the potential of an electrochemical cell $E$ and it provides information of how far from the equilibrium is the redox reaction. Equation (4) gives the Nernst equation (Pandey et al., 1996):

$$
E=E_{o}-\frac{R T}{n F} \ln \left[\frac{a p}{a r}\right]
$$

where, $E_{o}$ is the standard reference potential measured against $\mathrm{SHE}$, concentration $1.0 \mathrm{M}$, pressure 1 and temperature $25^{\circ} \mathrm{C}, R$ is the Gas constant, $T$ is the temperature in $\mathrm{K}, n$ is the number of electrons, $F$ is the Faraday's constant, $a p$ is the activity of products and $a r$ is the activity of reactants.

Electrodeposition from aqueous solution does not exceed $100^{\circ} \mathrm{C}$ because at this temperature the electrolyte starts to boil. The non-aqueous media such as ethylene glycol allow an increase in temperature $\sim 170^{\circ} \mathrm{C}$ (Premaratne, 2003). CdTe films deposition on Nickel substrate using non-aqueous solution containing AR-grade $\mathrm{CdCl}_{2}, \mathrm{KI}$ and $\mathrm{TeCl}_{4}$ in ethylene glycol has been reported (Gore et al., 1989). The stability of the bath is within the temperature ranges $25-180^{\circ} \mathrm{C}$. Ethylene glycol starts boiling at temperature greater than $180^{\circ} \mathrm{C}$. The deposition of CdTe takes place at temperature $\sim 160^{\circ} \mathrm{C}$.

\subsection{Theory of Electrodeposition}

5.3.1 Cyclic Voltammogram: This technique is used to identify the regions where the deposition of thin film material takes place. The electrical properties of species in a solution as well as at the electrode/electrolyte interface can be studied using cyclic voltammogram. Figure 11 shows a typical cyclic voltammogram of $\mathrm{CdTe}$ bath containing $1.0 \mathrm{M}$ $\left(3 \mathrm{CdSO}_{4} .8 \mathrm{H}_{2} \mathrm{O}\right), 4 \mathrm{ml} \mathrm{TeO}$ solution and $1000 \mathrm{ppm}$ $\mathrm{CdCl}_{2} \cdot \mathrm{H}_{2} \mathrm{O}$. Hydrogen evolution occurs at cathodic voltages above $1.20 \mathrm{~V}$ due to splitting of water molecules by hydrogen evolution which has disadvantage in one way or the other. The quality of the film being deposited deteriorates and sometimes falls away completely during vigorous $\mathrm{H}_{2}$ evolution. It is useful if not vigorous, as hydrogen passivation is automatically provided. 


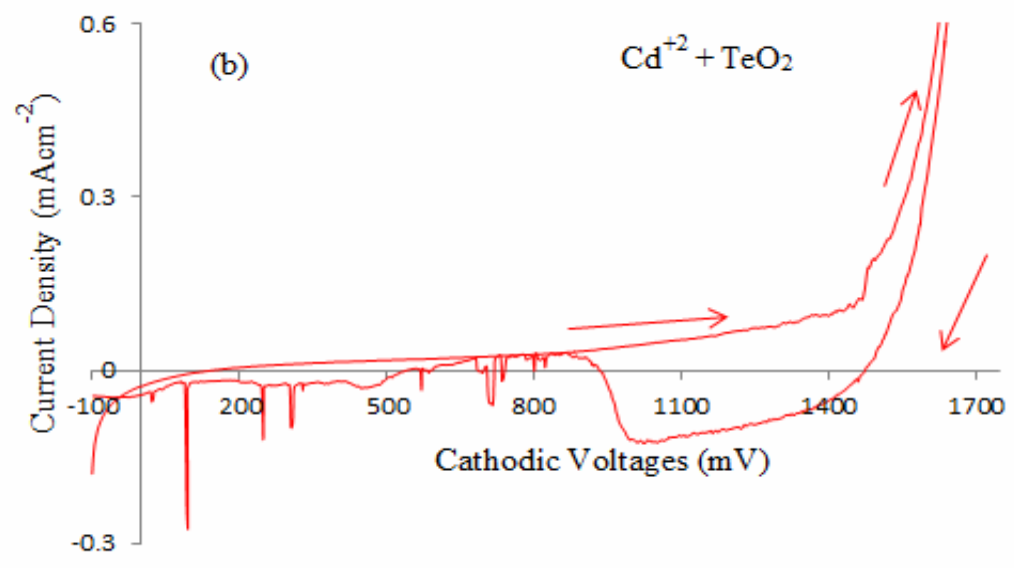

Figure 11: Typical cyclic voltammogram for electrolytic baths used for deposition of CdTe (Diso, 2011).

5.3.2 Pourbaix Diagram: A Pourbaix diagram shows the dependence of the deposition potential on the $\mathrm{pH}$ value of an electrolyte. It is an isothermal phase diagram, which represents metal-ion-oxide equillibria plotted with deposition potential and $\mathrm{pH}$ as coordinates. Parameters that can be assessed using this diagram include effect of $\mathrm{pH}$, oxidation potentials, corrosion etc. A Pourbaix diagram was used only as a guide to know exactly the stable $\mathrm{pH}$ of the CdTe bath condition. Figure 12 shows a Pourbaix diagram related to aqueous electrodeposition of CdTe thin film developed (Volushchuk et al., 2002). From the Figure, stability limits of solid CdTe are represented by lines 1 and 4 (lower limit) and 5, 11 and 12 (upper limit). This shows that CdTe is thermodynamically stable in this region. In acidic, neutral and basic solution at potential above the lower stability limits, hydrogen is released at the cathode. CdTe reduces to $\mathrm{Cd}$ and $\mathrm{H}_{2} \mathrm{Te}$ at $\mathrm{pH}$ values of 2.0 and cathodic potential greater than $-1.5 \mathrm{~V}$. Similarly, it corrodes to $\mathrm{Cd}^{2+}$ and Te at smaller cathodic potential less than $0.1 \mathrm{~V}$.

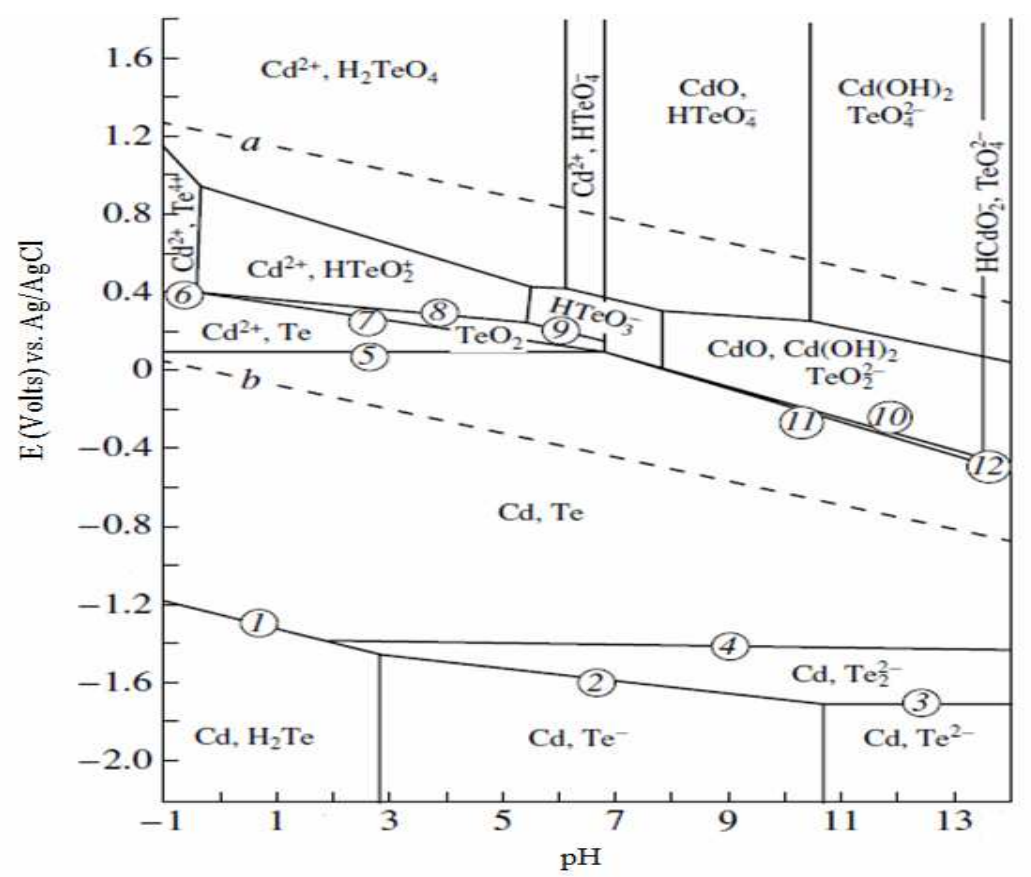

Figure 12: $\quad$ Pourbaix diagram of the $\mathrm{CdTe}-\mathrm{H}_{2} \mathrm{O}$ system (Voloshchuk, 2002).

5.3.3 Equations related to deposition of CdS and CdTe

(a) CdS thin films:CdS thin films were cathodically deposited from a solution containing $\mathrm{Cd}^{2+}$ and $\mathrm{S}^{2-}$ ions according to the following equations (MaCann et al., 1981):
The cathodic reactions leading to the formation of CdS formation are;

$$
\begin{aligned}
& \mathrm{Cd}_{(a q)}^{2+}+2 \bar{e} \rightarrow \mathrm{Cd}_{(s)} \\
& 2 \mathrm{Na}_{(a q)}^{+}+\mathrm{S}_{2} \mathrm{O}_{3}^{2-}{ }_{(a q)}^{(5)}+6 \mathrm{H}_{(a q)}^{+}+4 \bar{e} \rightarrow 2 \mathrm{~S}_{(s)}+3 \mathrm{H}_{2} \mathrm{O}
\end{aligned}
$$


The thiosulphate ion is:

$$
\mathrm{S}_{2} \mathrm{O}_{3(a q)}^{2-} \rightarrow \mathrm{S}_{(a q)}+\mathrm{SO}_{3}^{2-}
$$

The overall electrode reaction is given by equations 2.5 and 2.7 as;

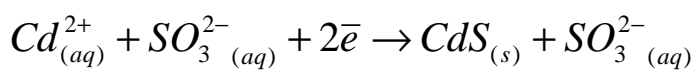

(b) CdTe thin film: The following are the equation related to CdTe thin film deposition (Danaher and Lyons, 1984):

Reduction of Tellurium;

$$
\begin{gathered}
\mathrm{HTeO}_{2(a q)}^{+}+3 \mathrm{H}_{(a q)}^{+}+4 \bar{e} \rightarrow T e^{(9)} \\
\text { of Tellurium with the } \mathrm{Cd}^{2+} \text { ions } \\
\mathrm{Te}_{(s)}+\mathrm{Cd}_{(a q)}^{2+}+2 \bar{e} \rightarrow C d T e_{(s)}
\end{gathered}
$$

Generally, the overall cathode reaction is

$$
\mathrm{Cd}_{(a q)}^{2+}+\mathrm{HTeO}_{2(a q)}^{+}+3 \mathrm{H}_{(a q)}^{+}+6 \bar{e} \rightarrow \mathrm{CdTe}_{(s)}+2 \mathrm{H}_{2}^{\mathrm{gggd}} \text { supervision during the research work. }
$$

\subsection{References}

Alamri, S. N. (2003) : The growth of CdTe thin film by close space sublimation system. Phys. Stat. Sol. a 200 (2): 352-360.

Ali A., Shah, N. A. and Maqsood A. (2008): Characterisation of CdTe thin films fabricatedby two source evaporation technique and Ag doping by ion exchange process. Solid State Electronics 52: 205-210.

Arita, T., Hanafusa, A., Ueno, N., Nishiyama, Y., Kitamura, S. and Murozona, M. (1991): CdS/CdTe solar cells with improved CdS films fabricated by the writing method. Solar Energy Material 23: 371-379.

Arthur, J. R. (2002): Molecular Beam Epitaxy. Surface Science 500: 189-217.

Berrigam, R. A., Maung, N, Iroine, S. J. C., ColeHamilton, D. J. and Ellis, D. (1998): Thin films of CdTe/CdS grown by MOCVD for photovoltaics. J. of Crystal Growth 195 (1): 718-724.

Berry, A. K. (1996): Doping Studies of SprayDeposited CdTe Films. Mater. \& Engineering B 8: $57-62$.

Boieriu, P., Sporken, R., Xin, Y., Browaning, N. D. and Sivawanthan, S. (2000): Wurtzite CdS on CdTe grown by molecular beam epitaxy. J. of Electronic Mater. 29 (6): 718-722.

Chopra, K. L. and Das, S. R. (1983): Thin Film Solar Cells. Plenum Press, New York: 312345

Choy, K. L. (2003): Chemical vapour deposition. Progress in Material Science 48: 57-170.

Combo, J. J. and Gambino, R. J. (1968): Electrochemical synthesis of III-V compounds. $J$.
Similarly, anode reaction is

$$
4 \mathrm{OH}^{-} \rightarrow \mathrm{O}_{2}+4 \bar{e}+2 \mathrm{H}_{2} \mathrm{O}
$$

Therefore, the formation of CdTe compound can be obtained from the cathode reaction.

\subsection{Conclusion}

During the growth of semiconductor, the deposited layer can be epitaxial or stranski-krastanov (S-K mode). The techniques used to grow CdS/CdTe thin film solar cells have been reviewed. Among the techniques highlighted, electrodeposition is the simplest and easiest way of thin film deposition when compared with vacuum deposition which requires very sophisticated equipment that operate at high temperatures.

\section{Acknowledgment}

Kano University of Science and Technology, Wudil, Kano-Nigeria is gratefully acknowledged for funding this research. The main author also wishes to acknowledge Professor I. M. Dharmadasa, Head, Electronics Materials and Sensors Group, Materials and Engineering Research Institute, Sheffield Hallam University, United Kingdom for immense guidance and Electrochem. Soc. 115 (7): 755-765.

Cunnigham, D. (2000): Energy Conservation Standards for External Power Supplies. Conf. rec. 16th EPSSEC: 281-305.

Danaher, W. J. and Lyon, L. E. (1978): Photochemical cell with CdTe film. Nature 271: 139-145.

Danaher, W. J. and Lyons, L. E. (1984): The kinetics of the electrodeposition of CdTe. Australian. J. Chem. 37 (4): 689-701.

Ddero, M. (1934): Chemical Vapour Transport Reactions-Methods. Compt. Rend. Acad. Sci. Paris 109: 556-570.

DeMattei, R. C., Elwell, D. and Feigelson, R. S. (1978): Conditions for stable growth of epitaxial GaP layers by molten salt electrodeposition. J. of Crystal Growth 43: 643-650.

Dennison, S. (1994): Dopant and impurity effects in electrodeposited CdS/CdTe thin films for photovoltaic applications. J. Mater. Chem. 4 (1): 41-46.

Deivanayaki, S., Jayamurugan, P., Mariappan, R. and Ponnuswamy, V. (2010): Optical and Structural Characterisation of CdTe Thin Films by CBD Technique. Chalcogenide Letters 7 (3): 159-163.

Dharmadasa, I. M. and Haigh, J. (2006): Strengths and Advantages of Electrodepositions as a Semiconductor Growth Technique for Applications in Macroelectronic Devices. J. Electrochem. Soc. 153 (1), G47-G52.

Diso, D. G. (2011): Research and Development of CdTe Thin Films Solar Cells. PhD Thesis. Sheffield Hallam University, United Kingdom: 122. 
Gore, R. B., Pandey, R. K. and Kulkarni, S. K. (1989): Investigation of deposition parameters for the non-aqueous electroplating of CdTe films and application in electrochemical photovoltaic cells. Solar Energy Materials 18: 159-169.

Green, M. A., Emery, K., Hisikawa, Y. and Warta, W. (2007): Solar cell efficiency tables. Prog. Photovolt: Res. Appl. 15: 425-430.

Han, J., Liao, C., Jiang, T., Spanheimer, C., Haindl, G., $\mathrm{Fu}, \mathrm{G}$. , Krishnakumar, V., Zhao, K., Klein, A. and Jaegermann, W. (2010): An optimized multilayer structure of CdS layer for CdTe solar cells. J. of Alloys \& Compounds. doi:10.1016/j.jallcom.2010.12.085.

Hodes, G., Manassen, J. and Cahen, C. (1976): Electrochemical energy conversion and storage using polycrystalline chalcogenide electrodes. Nature 261: 402-404.

http://wwwold.ece.utep.edu/research/webedl/cdte/Fa brication/index.htm, Ret. October, 2015.

Kumar, V., Gaur, J. K., Sharma, M. K. and Sharma, T. P. (2006): Electrical properties of CdTe screen-printed films for photovoltaic applications. Chalcogenide Letters 5(8), 171.

Lee, Y. H., Lee, W. J., Kwon, Y. S., Yeon, G. Y. and Yoon, J. K. (1999): Effects of CdS substrates on the physical properties of polycrystalline CdTe Films. Thin Solid Films 341: 172-178.

Luque A. and Hegedus, S. (2003): Handbook of Photovoltaic Science and Engineering. John Wiley \& Sons, Ltd., U.S.A: 609.

MaCann, J. F. and Skyllas, K. M. (1981): The electrochemical deposition and formation of CdS thin film electrodes ir aqueous electrolytes. J. Electroanal. Chem. 119: 409418.

Mandal, S. K., Chaudhuri, S. and Pal, A. K. (1999): Nanocrystalline CdTe films deposited by high-pressure sputtering: carrier transport at low temperature. Thin Solid Films 357: 102110.

Miller B. and Heller, A. (1976): Semiconductor liquid junction solar cells based on anodic sulphide films. Nature 262: 680-683.

Pandey, R. K., Sahu, S. N. and Chandra, S. (1996): Handbook of Semiconductor Electrodeposition. Marcel Dekker, Inc. New York: 208.

Panicker, M. P. R., Knaster, M. and Kröger, F. A. (1978): Cathodic deposition of CdTe from aqueous electrolytes. J. Electrochem. Soc. 125: $566-570$
Parashkov, R., Becker, E., Riedl, T., Johnnes, H-H and Kowalsky, W. (2008): Large area electronics using printing methods. In Proc: IEEE 93 (7): 1321-1329.

Patil, P. S. (1999): Versatility of chemical spray pyrolysis technique. Materials Chemistry and Physics 59: 185-190.

Pierson, H. O. (1999): Handbook of Chemical Vapour Deposition (CVD): Principles, Technology and Applications, $2^{\text {nd }}$ edition. Noyes Publication, Park Ridge, NJ U.S.A.: 315

Premaratne, K., Akuranthilaka, S. N., Dharmadasa, I. M. and Samantilleka, A. P. (2003): Electrodeposition using non-aqueous solutions at $170^{\circ} \mathrm{C}$ and characterisation of $\mathrm{CdS}, \mathrm{CdS}_{\mathrm{x}} \mathrm{Se}_{(1-\mathrm{x})}$ and $\mathrm{CdSe}$ compounds for use in graded bandgap solar cells. Renewable Energy 29: 549-559.

Seth, A., Lush, G. B., McChue, J. C., Singh V. P. and Flood, D. (1999): Growth and characterisation of CdTe by CSS on metal substrates. Sol. Energy Mater. Sol. Cells 59: 35-41.

Smehtkowski, V. S. (2000): Trends in sputtering. Prog. in Surface Science 64: 1-22.

Taneja, P., Vasa, P. and Ayyub, P. (2002): Chemical passivation of sputter-deposited Nanocrystalline CdS thin films. Material Letters 54: 343-355.

Tekin, E., Smith, J., Hoeppener, S., Vanden Berg, A. M. J., Susha, A. S., Rogach, A. L., Feldmann, J. and Schubert, U. S. (2003): Inkjet printing of luminescent CdTe nanocrystal-polymer composites. Advance Functional Materials 17, 23-31.

Toušková, J., Kindl, D. and Konanda, J. (1992): Preparation and fundamental properties of $\mathrm{CdS} / \mathrm{CdTe}$ heterojunctions. Thin Solid Films 214: 92-98.

Ullik, F. (1865): Electrodeposited from a molten fluoride mixture. Ber. Akad. Wien 52: 115120.

Voloshchuk A. G. and Tsipishchuk N. I. (2002): Equilibrium Potential-pH Diagram of the CdTe- $\mathrm{H}_{2} \mathrm{O}$ System. Inorganic Materials 38 (11): 1114-1120.

www.firstsolar.com, Retrieved July, 2014. 